Gerión. Revista de Historia Antigua

ISSN: 0213-0181

http://dx.doi.org/10.5209/GERI.56957

\title{
La concepción del feto en la legislación romana: entre la esperanza y la herencia
}

\author{
Patricia González Gutiérrez ${ }^{1}$
}

Recibido: 28 de marzo de 2016 / Aceptado: 6 de enero de 2017

Resumen. La existencia del feto supuso un reto para la legislación romana, ya que suponía una intersección entre diversos derechos familiares y personales, pese a que el mismo no fuese considerado propiamente como una persona. Los diversos problemas y soluciones que fueron apareciendo a lo largo de la historia romana nos permiten acercarnos a la forma en que concebían la sociedad, al individuo, la familia y las construcciones de género.

Palabras clave: feto; derecho; género; familia.

\section{[en] The Concept of the Fetus in Roman Law: between Hope and Inheritance}

\begin{abstract}
The mere existence of the fetus is a challenge to Roman law, since it involved an intersection between various family and personal rights, although it was not considered as a proper person. The various problems and solutions that appeared throughout Roman history allow us to approach the way they conceived society, the individual, family and gender constructions.
\end{abstract}

Keywords: Fetus; Law; Gender; Family.

Sumario. 1. Introducción. 2. El feto en Roma. 3. Relación materna y garantías legales. 4. La autoridad paterna. 5. Los póstumos y la herencia. 5. Líneas de sangre. 7. Liberi y monstra. 8. Conclusiones. 9. Referencias bibliográficas.

Cómo citar: González Gutiérrez, Patricia (2017) La concepción del feto en la legislación romana: entre la esperanza y la herencia, en Gerión 35/1, 99-116.

\footnotetext{
Universidad Complutense de Madrid

E-mail: pagonz03@ucm.es
} 


\section{Introducción}

En los últimos años se ha incrementado el número de trabajos relativos a la maternidad, la paternidad o el control de la natalidad en el mundo antiguo. El auge de la historia de género $y$, posteriormente, de la historia de la infancia ha puesto el foco en ciertos temas que antes tendían a obviarse y ha creado debates nuevos. Dentro de ellos, el asunto de la consideración de los niños, tanto legal como social, ha sido objeto de una amplia controversia. La visión negativa de autores como Philippe Ariès o Lloyd DeMause, que consideraban que no existía una idea de infancia como tal o que el pater familias tenía un poder absoluto, ha sido contrastada por otro tipo de trabajos, más matizados, como los de Linda Pollok o Louis Haar. ${ }^{2}$ Estos nuevos enfoques, que no descartaban las relaciones afectivas en el seno de las familias y que daban una mayor agencia a los niños, permitieron también una concepción más conmpleja de las familias, en la que entraban las variaciones entre individuos o las contradicciones internas en las diversas sociedades. ${ }^{3}$

Así mismo, el estudio de la maternidad en el mundo antiguo ha tenido un auge paralelo en la historiografía, centrándose tanto en los discursos desde el poder, claramente pronatalistas, como en el ámbito más doméstico o en las ideas médicas sobre el embarazo o el parto. En España, grupos de investigación como el creado en la Universidad de Oviedo, el grupo Démeter, y obras colectivas como las de Carmen Suárez, ${ }^{4}$ Silvia Tubert ${ }^{5}$ o Rosa María Cid López ${ }^{6}$ demuestran la vitalidad de este campo.

También se han ido planteando nuevas polémicas en torno a la legalidad, aceptación o valoración del aborto y la anticoncepción. Después de obras de gran aceptación como las de Angus McLaren o Enzio Nardi vinieron nuevas visiones, mucho más polémicas, como las de John M. Riddle o Konstantinos Kapparis. El primero ha sido muy criticado por investigadores como Helen King o Walter Scheidel, acusándole de reduccionista o de contar cuentos románticos sobre mujeres sabias que transmiten un conocimiento médico al margen de la autoridad masculina. El segundo ha sido acusado, por ejemplo por Nancy Demand, de anacrónico, cuestionando sus conclusiones tanto como su metodología. A pesar de estas críticas, las nuevas polémicas sobre la consideración del feto, del control de la natalidad o los distintos puntos de vista de grupos sociales diferentes en la Antigüedad, han resultado de enorme interés para la historiografía.

Un elemento de intersección entre estos campos es el del carácter legal y la consideración social del feto, algo que no ha sido, en muchos casos, suficientemente tratado cuando se estudian estos temas. Para ello es necesario acudir, sobre todo, a las fuentes legales, pero también hay que tener en cuenta las ideas del mos maiorum referidas a los valores familiares y cívicos. No pueden comprenderse las visiones romanas referidas a los derechos del feto o la moralidad del aborto sin entender cómo funcionaban las relaciones de poder intrafamiliares o las asociaciones con temas como la magia o el adulterio. Por otro lado, y en un sentido inverso, el estudio de las leyes generales y casos particulares referidos al nonato nos ayuda a desentrañar esas redes de autoridad y su evolución en la historia de Roma.

Brockliss - Montgomery 1994, passim; SAller 1994, passim.

Entre otros, George 2005; Saller 1994; Mustakallio 2005; CraWford - Sheperd2007; Dasen - Späth 2010.

SuÁrEZ 2009.

Tubert 1996.

Cid López 2009. 
En cualquier caso, este tipo de investigaciones se encuentran siempre con las dificultades inherentes al estudio de la legislación y la sociedad romana. La mayor parte de las leyes que conservamos provienen de recopilaciones tardías, como el Digesto o el Código de Teodosio, por lo que muchas veces existen problemas para datar de forma exacta una ley en concreto o saber el alcance real de una norma, tanto en el marco temporal (algunas normas simplemente caían en desuso, sin ser, técnicamente, abolidas) como en su cumplimiento por parte de la población. Por ello hay que ser cautos con una visión homogénea a lo largo de la historia romana y ser conscientes de la posible invisibilización de muchos cambios o contradicciones entre la legislación oficial y los usos cotidianos reales.

\section{El feto en Roma}

La situación y derechos del feto suponían, para la legislación romana, un asunto delicado. Por un lado, requería una cierta definición del mismo, y, por otro, de cómo afectaba un nacimiento a la posición de los distintos miembros de la familia. Para ello se hacía necesario conjugar toda una serie de creencias religiosas, sociales y médico-científicas, además de los intereses particulares de las familias y del Estado.

Para el derecho romano el feto no era, en ningún caso, una persona. Tampoco lo era para la medicina, ni parece que lo fuera según la opinión general. Era común referirse al feto como "lo que se lleva en el vientre" (kata gastrós) o como animal (zôon/animal). ${ }^{7}$

Tan solo en ciertos ambientes morales extremos se aceptaba una humanidad previa al nacimiento. ${ }^{8}$ Aunque su condición de ser viviente sí era algo más disputado entre los filósofos y médicos, siendo un tema central en algunas reflexiones de Galeno, Clemente de Alejandría o en la obra pseudo-plutarquea titulada, precisamente ¿Lo que está en el vientre es un ser vivo?, ${ }^{9}$ este debate no tiene un reflejo en la legislación, poco interesada en el tema de la formación del feto o su hominización. Las palabras más usuales en latín, como conceptus, nasci speratur o in utero est, dan una idea neutra del nasciturus, que no se concibe como persona. En general, se considera que está in rerum naturam pero no in rebus humanis. Aún así, en ciertos casos adquiriría algunos de los derechos de una persona ya nacida bajo ciertas condiciones, sobre todo en el derecho tardío.

Aunque las percepciones sociales sobre el feto, el aborto o la anticoncepción fueron cambiando con el auge del cristianismo, ${ }^{10}$ estas ideas tardaron en llegar a la legislación, por lo que las recopilaciones tardías, como el Digesto o las Instituciones de Gayo, mantienen, en gran medida, una visión patrimonial e instrumental del mismo.

Resulta curioso que, pese al creciente interés por el feto, el cristianismo primitivo se caracterizara precisamente por una ruptura de los lazos familiares, al poner la fe por encima del control social que suponía la institución familiar. Solo con el paso del tiempo se fue insistiendo nuevamente en la sumisión femenina a unos modelos

KAPPARIS 2002, 36 y ss.

ESCOBAR 2012, 109-122.

Congourdeau 2004, 349-350.

10 Sobre el discurso cristiano que carga de mayor negatividad la sexualidad, la anticoncepción o la corporalidad, cf. NOONAN 1969; BROWN 1993. 
maternales y familiares, sustituyendo el martirio real por un "martirio blanco" y doméstico. ${ }^{11}$

Al analizar estos temas debemos desligarnos, además, de las percepciones actuales sobre la infancia, la esperanza de supervivencia de los niños o sus derechos propios por el hecho de serlo y ser conscientes de que estas visiones difieren sustancialmente de las que tenían las sociedades premodernas.

\section{Relación materna y garantías legales}

La legislación es garantista con la condición jurídica del feto. Así, en el caso de que la madre fuese esclavizada durante el mismo, el feto seguía siendo libre, pero si la mujer era esclava y era liberada, el feto también adquiría la condición libre. ${ }^{12} \mathrm{En}$ el caso de esclavas legadas o alienadas, parece haber una tendencia a mantener el vínculo de la madre con el hijo, legislándose sobre la pertenencia del hijo a quien tuviera a la madre en el momento del parto. En cualquier caso, prima el derecho del comprador, que adquiere tanto a la esclava como su embarazo, pese a que este hubiera sido concebido estando la madre en propiedad de otra persona, ${ }^{13}$ aunque se distingue claramente el parto de las esclavas del fruto de la procreación del ganado. ${ }^{14}$ En cualquier caso, es claro el debate en los casos de conflicto, en caso de hurto de una esclava embarazada y otro tipo de problemas con el parto de una esclava, incluyendo su definición. ${ }^{15}$

La norma que indica la libertad del feto en caso de que su madre fuera libre en cualquier momento dio lugar a algunos casos curiosos. Uno de estos ejemplos viene de la intersección con la norma que establecía que una esclava con tres hijos adquiría inmediatamente la libertad. Esto podía provocar dudas en caso de que la esclava hubiera tenido dos veces gemelos o un hijo y luego trillizos. La legislación, en este caso, establece que solo el último hijo en salir del vientre materno es libre, ya que considera que la mujer sería libre solo a partir de haber parido el tercer hijo, no contando la mera concepción en este caso. ${ }^{16}$

La misma garantía se daba en caso de que el feto fuera concebido antes de la condena de su madre, ${ }^{17}$ ya que el hijo nacería de la condición que tuviera la madre antes de la condena, y no esclavo si la pena convertía a esta en esclava (como sucedía en muchas ocasiones). Lo mismo sucede con el derecho a la herencia si alguno de los padres fuera condenado después de la concepción del hijo, pero antes de su nacimiento. ${ }^{18}$ Además de la legislación sobre el derecho a herencia en este caso, se garantiza también que una posible condena a muerte de la madre fuera aplazada. ${ }^{19}$ En el caso de la tortura aplicable para obtener una confesión válida, también tendía a aplazarse, para no poner en riesgo el feto. ${ }^{20}$ En el Código de Justiniano, también

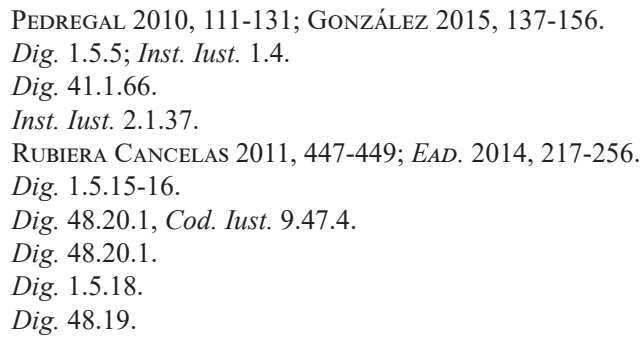


se especifica que la parte de los bienes de un condenado a muerte o a deportación se guarda para los hijos, incluyendo los póstumos. ${ }^{21}$

Aun así, no queda claro que hubiera una cierta sensación de respeto por la vida del feto, o derecho a la vida por su mera existencia, sino que entrarían en juego una serie de intereses paternales. Hay que tener en cuenta que los hijos serían agnados del padre, pero solo cognados, un vínculo claramente más débil, de la madre, por lo que la ejecución de una embarazada perjudicaría a terceros. ${ }^{22}$

Esta débil relación legal de la madre con sus hijos contrasta vivamente con la enorme presión social y religiosa que existía sobre el deber de la maternidad para la mujer, no solo dentro de la familia, donde los hijos afirmarían su posición dentro del matrimonio, sino también de cara a sus obligaciones cívicas con el Estado. La relación entre la guerra y el parto, como obligaciones masculina y femenina, se hace presente en todo el mundo antiguo, y Roma no era una excepción. ${ }^{23}$

De hecho, en las leyes augusteas sobre el matrimonio, con una fuerte carga de propaganda sobre la recuperación de la moralidad y el retorno a un pasado dorado, no solo se hace énfasis en el castigo del adulterio o la dignificación del matrimonio, sino también en medidas fuertemente pronatalistas. Así, mediante esta fertilidad abundante se podían conseguir importantes ventajas legales, a través del ius trium liberorum, tanto para el padre como para la madre, que podía conseguir, por ejemplo, la liberación de la tutela. La mujer esclava podía obtener también su libertad a través de la maternidad, reforzando la carga simbólica y social de la misma.

Estas leyes se complementaron con medidas de visibilización de la fertilidad, como la erección de una estatua a una esclava que había tenido muchos hijos, o procesiones con familias especialmente numerosas. ${ }^{24}$ Así, la fertilidad de las mujeres, de la naturaleza y el poderío y riqueza del Estado se entrelazaban en un potente discurso sobre la moralidad y la maternidad.

En cualquier caso, aunque, legalmente, la familia de la mujer acabara en sí misma, ${ }^{25}$ este tipo de vínculos se limitaban a cuestiones de potestad sobre los hijos, herencias y otras cuestiones similares, ya que para otros casos, como el del incesto, se reconocían todos los vínculos de sangre. Así, estaría penado, por ejemplo, el matrimonio de un hombre con su hermana ilegítima, aunque no hubiera ningún vínculo legal entre ellos como familia. De hecho, la pena sería la muerte o la deportación, y no solo la anulación del matrimonio. ${ }^{26}$

De este modo, la legislación también se preocupa por la tutela del futuro hijo, de manera similar a la propiedad en el caso de esclavas. En el supuesto, por ejemplo, de que la mujer concibiera y luego el abuelo emancipara al hijo, el nieto estaría aun bajo la autoridad del abuelo. ${ }^{27}$

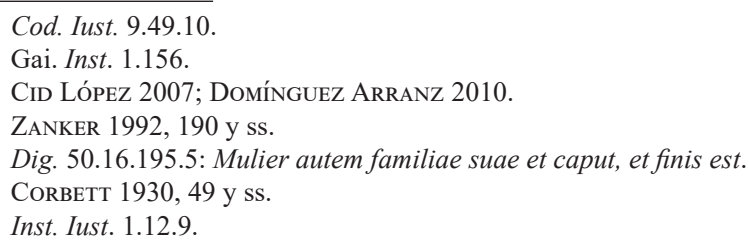




\section{La autoridad paterna}

Del mismo modo, la legislación más clara sobre el aborto, el conocido rescripto de Caracalla y Septimio Severo, no pena la muerte embrionaria intencionada como un homicidio, sino como una sustracción de un bien al padre, que tiene más derecho legal sobre el hijo que la madre, ${ }^{28}$ ya que era su agnado y no solo su cognado.

Este modelo social se justifica en el modelo biológico, a la vez que la biología parte de unos conceptos básicos incuestionados que surgen de la jerarquización social. Así, se forma un círculo vicioso que asienta los cimientos de un sistema de gran pervivencia. Hay que tener en cuenta que, pese a que algunos autores greco-romanos propusieron un sistema de doble semilla (Demócrito de Abdera, Epicuro o algunos fragmentos hipocráticos), en general se sostenía que el embrión se formaba por la acción de la semilla paterna, siendo la mujer un mero receptáculo. Así lo transmitieron autores como Aristóteles, Varrón o Galeno, marcando la línea médica predominante. En cualquier caso, es significativo que sea la participación activa de la mujer en la generación, la que parecería más obvia, la que se discute en la medicina antigua. ${ }^{29}$

Esta idea de la mujer como tierra o vaso forma parte de la cultura popular y el imaginario colectivo de forma muy potente, reforzando la idea de vinculación de los hijos con el padre y no con la madre. Esquilo en las Euménides ${ }^{30}$ o Eurípides en Orestes ${ }^{31}$ reducen el papel femenino al de mera portadora de la nueva vida, y en el latín amoroso la metáfora de la mujer como tierra que debe ser arada y sembrada es habitual. ${ }^{32}$ Loraux señala la importancia de la tierra y de la invisibilización de la participación femenina en la reproducción como base de los mitos de autoctonía y de la afirmación de la dominación masculina, así como del control del cuerpo femenino. ${ }^{33}$

Hasta tal punto se cuidaban los derechos del padre en la legislación romana que surgió una figura, la del custos ventris, encaminada a vigilar los embarazos y partos problemáticos legalmente. ${ }^{34}$ El Digesto nos habla de la obligación de la mujer de notificar al marido del que se hubiera divorciado un posible embarazo. Si bien no estaba obligada a ello si el hijo no fuera del antiguo marido, este podía, en cualquier caso, mandar observadores. En caso de que la mujer se negara, y negara el embarazo, podía ocurrir que el padre se negara a reconocer al hijo sin penalización alguna. ${ }^{35}$

Si el marido insistía, podía llegar a obligar legalmente a que la mujer fuera examinada por tres comadronas (elegidas por el pretor y no por ninguna de las partes implicadas), aunque la ley advertía al marido que esto suponía poner en juego el honor familiar por ambas partes. Si, al menos, dos de las comadronas declaraban que estaba embarazada, se instituía un guardián, el custos ventris, para evitar que la mujer abortase, se deshiciese del niño o lo cambiase en el parto. ${ }^{36} \mathrm{Si}$ la mujer resultaba

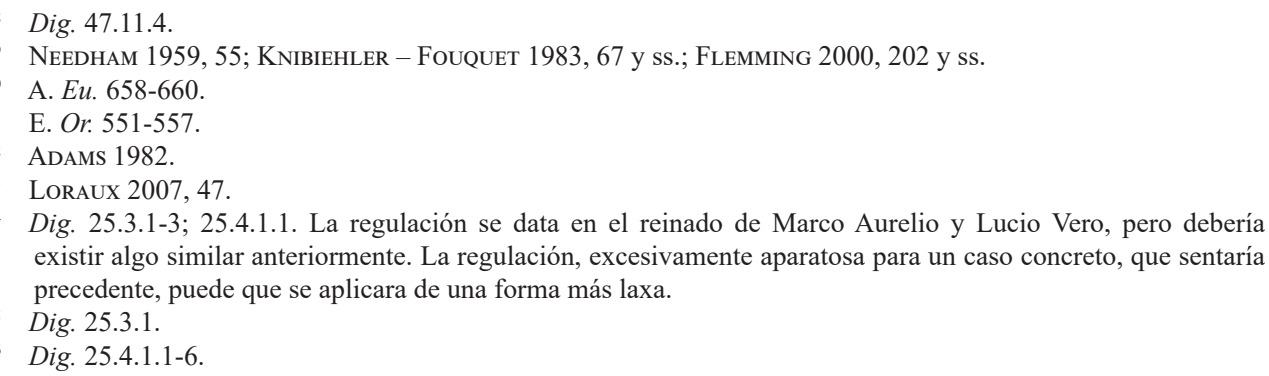


decir la verdad podía iniciar un proceso por injurias contra el antiguo marido. ${ }^{37}$

El parto también estaría sujeto a vigilancia, produciéndose en una habitación sin ventanas, con solo una puerta y cinco mujeres ingenuas como testigos, además de vigilarse la entrada por seis personas y tener que estar en una casa respetable. Se establecía incluso la necesidad de una iluminación adecuada y la revisión de toda persona que entrase en la habitación. ${ }^{38}$ Lo exagerado de estas disposiciones lleva a dudar de la frecuencia de este tipo de actuaciones, aunque las ocasiones de conflicto serían lo suficientemente habituales como para que se llegara a legislar sobre ello. De cualquier modo, este tipo de actuaciones se darían a partir del gobierno de Marco Aurelio y Lucio Vero, ya que el caso recogido por Ulpiano, el de Rutilio Severo y Domicia, se califica como algo nuevo. ${ }^{39}$ Puede suponerse algún tipo de medidas preventivas anteriores, que cristalizarían en esta norma en un caso extremo.

No puede olvidarse, por otro lado, la existencia de episodios que contradicen este tipo de sentencias, y que se darían si existía consenso familiar en torno al futuro del hijo. Un caso recogido en el Digesto muestra la despreocupación del padre al repudiar a su esposa embarazada. Esta no aborta, pero expone al hijo, y solo tras la muerte del padre, que le había dado por muerto sin mayores problemas, el abuelo paterno reconoce al nieto. Este proceso no es recogido por la ilegalidad o conflicto en ninguna de estas acciones, sino por la validez del testamento paterno en que no se recoge la existencia del hijo, consultándose sobre la validez de las manumisiones realizadas en el mismo. ${ }^{40}$

Lo mismo sucedía en la normativa griega y así, por ejemplo, en las leyes de Gortina (en las que la mujer tiene un estatus y una independencia relativamente altos), la madre separada que da a luz un hijo de su ex marido tras el divorcio se veía en la obligación de ofrecérselo a su antiguo cónyuge (o al dueño de su marido en el caso de que este fuera esclavo) delante de tres testigos. Tan solo si el padre rechazaba hacerse cargo del hijo podía la madre decidir si criarlo o exponerlo. Si bien es cierto que el castigo si decidía no hacerlo era meramente pecuniario. ${ }^{41}$

Pese al evidente dominio del padre sobre los hijos, primando sobre cualquier derecho de la mujer, hay casos en que parece que la madre va ganando capacidad y poder respecto a sus propios hijos, ya que Ulpiano recoge que, pese a que la potestad sobre un hijo la tenga el padre, pueden darse excepciones en que sea la madre la que lo retenga, pasando por encima de la autoridad paterna, al menos desde Antonino Pío. ${ }^{42}$

Lo mismo parece entreverse en la inspección que debe hacerse a la mujer en el caso de sospecha de embarazo tras el divorcio. No solo puede forzarse al padre a reconocer y criar al hijo, sino que Ulpiano, comentando los derechos del padre sobre el hijo, recoge tan solo que puede pedir que se le muestre. En estos casos, el hecho de llevarse el padre al hijo sería algo solo extra ordinem y bajo la asistencia y permiso del emperador. ${ }^{43}$

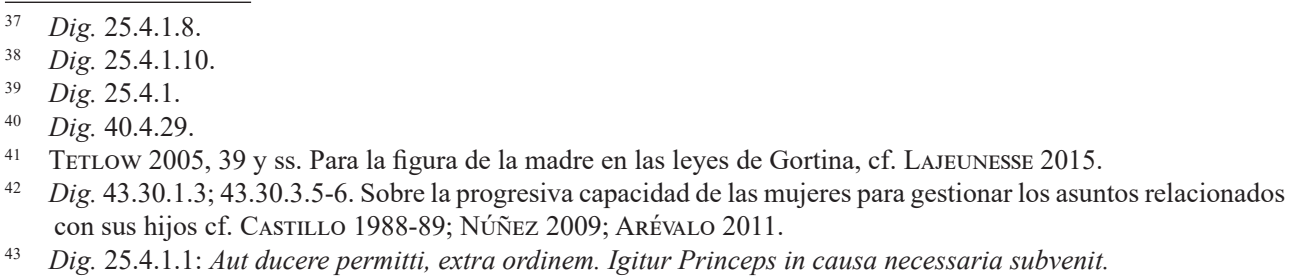

43 Dig. 25.4.1.1: Aut ducere permitti, extra ordinem. Igitur Princeps in causa necessaria subvenit. 


\section{Los póstumos y la herencia}

El embarazo creaba también, por sí mismo, una nueva situación en las líneas de herencia. Hay una amplísima normativa sobre los casos de los hijos póstumos y su derecho a herencia, que adquiría en el momento de su concepción. Si nacía un póstumo no nombrado en el testamento este se anularía, aunque esta anulación no sería válida en caso de que hubiera un aborto y el niño no llegara a nacer, o si se desheredara expresamente a cualquier póstumo que pudiera nacer. ${ }^{44}$ En la norma no se dice nada de que el aborto fuera espontáneo o se aceptara un aborto provocado para evitar dicha anulación. Cicerón recurre a algunos de estos casos en su defensa de Aulo Cluencio. En el discurso se acusa a un hombre, Opiánico, de haber cometido distintos crímenes para asegurarse una sustanciosa herencia, entre ellos el matar a la mujer de su hermano para evitar que concibiese, o el haber pagado a la mujer de su tío para que abortase de su hijo póstumo y evitar así fragmentar esa herencia. ${ }^{45}$ Aún así, no parece que haya una legislación clara a la que pueda acogerse y los casos de condenas que se encuentran en las fuentes resultan, en muchas ocasiones, exageraciones retóricas o recursos oratorios. Un caso muy claro es el recogido por Cicerón y, luego, en el Digesto por Trifoniano, sobre una mujer milesia embarazada que se habría provocado el aborto tras haber recibido por ello un pago por parte de los herederos. La condena a muerte de la mujer es claramente una mera treta retórica usada por Cicerón para reforzar la parte débil del argumento contra Opiánico, la del aborto, menos importante que la de la muerte de la propia mujer y del hermano. De hecho, en el Digesto la pena normal es el destierro temporal, reconociendo lo extraño de la condena a muerte. ${ }^{46}$

Hay que recordar que Musonio Rufo afirma que los legisladores antiguos habrían prohibido la anticoncepción y el aborto, en un claro recurso retórico, ya que la crítica que está realizando es, precisamente, a las prácticas antinatalistas de las familias romanas. ${ }^{47}$ Lo mismo sucede con la obra atribuida a Galeno sobre la naturaleza del feto, en la que se sostiene la existencia de unas supuestas legislaciones contrarias al aborto desarrolladas por Solón y Licurgo ${ }^{48} \mathrm{El}$ recurso a la tradición griega no resulta solo de un intento de dotar de un argumento de autoridad al texto, sino probablemente también de la ausencia de una legislación clara y comúnmente aplicada a estos casos, ya que, de lo contrario, aparecería sin duda de manera manifiesta.

De hecho, el aborto provocado se encuentra solo como motivo de divorcio en época tardía, sin que parezca que la legislación fuera más allá en muchas ocasiones, aunque pudiera haber penas accesorias. Junto con el aborto se añaden otras causas relacionadas con la lujuria femenina, como el caso de que la mujer se bañara con otros hombres o si fuera a espectáculos sin permiso de su marido, por lo que parece que la práctica se pena por la asociación con el adulterio más que por sí misma. ${ }^{49}$

Los póstumos, pues, tienen un derecho especial respecto a la herencia paterna y una condición especial dentro de la legislación. De hecho, mientras que no se podían




dejar legados a personas inciertas, sí se podían dejar a los póstumos, incluso si eran ajenos..$^{50}$ La posibilidad de que se anulara un testamento antiguo por el hecho del nacimiento de un póstumo hacía que se permitiese, incluso, mencionarlos en el caso de ser soltero el testador en el momento de realizar el documento, ${ }^{51}$ aunque también podía desheredársele más fácilmente que a un hijo vivo. ${ }^{52}$

En cualquier caso, estas medidas se encuadran dentro de un marco de protección general de los herederos legítimos, para evitar una excesiva dispersión del patrimonio familiar o casos de injusticia con los hijos. Estos derechos de los hijos sobre la herencia familiar se completan con otras normas, como las leyes Cincia, Furbia, Voconia o Falcidia, que restringían los legados, regalos o la capacidad del padre de ampliar el número de familiares incluidos en el testamento. ${ }^{53}$ En estas leyes de protección del patrimonio se definía, además, el reconocimiento de lo que se consideraba familia, en un sentido amplio en el que se incluían sui heredes, agnados, cognados y adfines, limitando al sexto grado la pertenencia al grupo familiar. Este límite era válido para otras restricciones, como la prohibición de matrimonio o el ius osculi. ${ }^{54}$

Los póstumos también adquieren el derecho a que se les deje establecido un tutor legal, como se hubiera hecho en el caso de haber muerto su pater familias después de nacido el niño. ${ }^{55}$ La madre, en principio, estaba excluida de cualquier tipo de tutela sobre el infante ${ }^{56}$ aunque esto iría evolucionando, pudiendo acceder a ella mediante permiso imperial y siempre que no contrajera nuevas nupcias. ${ }^{57}$ Incluso se dieron casos muy excepcionales de adopción por parte de una mujer. ${ }^{58}$

También se acaba regulando la vinculación de los hijos con la madre, en el caso de que esta muriera en el parto, teniendo derecho tanto a la porción civil como a la opción de demandar el testamento. ${ }^{59}$ En el Digesto se reconocía la capacidad de ese hijo de entrar en bonorum possessio de las propiedades, bien unde proximi cognati, o bien unde legitime tras el SC Orphitianum..$^{60}$ Aun así, se mantiene la prioridad de la agnación con el padre, y los hermanos uterinos (póstumos o no) no podían presentar querellas por testamento inoficioso, reservada a los que tuvieran un mismo padre. ${ }^{61}$

\section{Líneas de sangre}

Dentro de esta preocupación por la condición de los póstumos, su legalidad y derechos, existe una variante importante, la de la seguridad de la paternidad de los mismos. Dentro de este ámbito la primera preocupación es el tiempo de formación del feto, ya que resultaría básico en caso de duda sobre la posibilidad de que un hijo hubiera sido concebido aún en vida de su padre. Hay que tener en cuenta que,

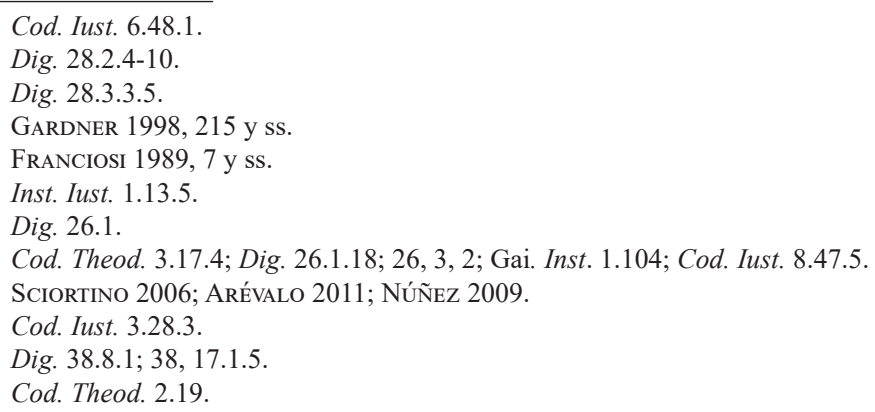


aunque la madre fuera siempre segura, la paternidad dependería exclusivamente de la legalidad de las nupcias y el nacimiento, sobre todo en caso de no poder ser reconocido el hijo por el padre. ${ }^{62}$

Algunos casos parecerían obvios, pero, aun así, la legislación se pronunciaba sobre ellos, probablemente debido a procedimientos particulares. Así, si un marido se había ausentado durante un periodo largo, y se hubiera encontrado a la vuelta un hijo claramente menor a ese periodo, no tendría obligación de reconocerlo (se pone el ejemplo de un hombre que se ausenta diez años y se encuentra un hijo de uno). O si el marido, por enfermedad o por otra causa, no hubiera tenido relaciones con su mujer $\mathrm{y}$, aun así, esta hubiese quedado embarazada, tampoco se consideraba hijo suyo. ${ }^{63}$

La segunda precaución estaría relacionada con evitar que la madre pudiera tener contactos sexuales que pusieran en duda la paternidad del hijo. Por ello se establece un periodo de luto obligatorio, evitando que contraiga matrimonio en ese periodo. Este se establece en los diez meses. Mientras Séneca menciona un periodo de luto de entre diez meses y un año para las mujeres que pierden a sus maridos, ${ }^{64} \sin$ mencionar la causa, Ovidio es más explícito. Este autor afirma que Rómulo había establecido un periodo de nueve meses completos para el luto de la mujer, pues era el tiempo que duraba un embarazo. ${ }^{65}$

La norma se sigue repitiendo en los códigos más tardíos, como en el de Teodosio, en el que se especifica que la mujer que rompa el luto de su marido perdería los derechos y dignidades de una persona honorable, así como toda protección imperial o toda propiedad de su anterior marido. ${ }^{66}$ El Código de Justiniano mantiene el periodo legal en diez meses, pero recomendando, por costumbre y como ya había mencionado Séneca, un luto de un año completo, para alejar cualquier tipo de duda. ${ }^{67}$

Estas disposiciones afectaban también a quien tuviera una mujer al cargo, ya que incurriría en infamia si no respetaba el periodo de luto de aquella. Lo mismo pasaría con el nuevo marido si conocía la situación previa. ${ }^{68}$ Como la normativa solo afectaba a las mujeres casadas, cuya maternidad pudiera convertirse en dudosa, no se castigaba a las mujeres que se prometiesen en el periodo de duelo y contrajesen matrimonio una vez hubiese acabado. Tampoco tenían duelo las mujeres que perdiesen un prometido ni los maridos que se hubiesen quedado viudos. ${ }^{69}$ Del mismo modo, el duelo por los parientes no impedía el matrimonio, además de que el parto de la mujer en duelo eliminaba la prohibición del matrimonio, pudiéndose casar inmediatamente. ${ }^{70}$

También es curiosa la noticia de Plutarco $^{71}$ sobre la disposición regia de la ausencia de luto por un niño menor de tres años. En niños mayores de esa edad, el luto adecuado sería de un mes por cada año de vida, teniendo un luto equivalente al de un adulto sobre los diez o doce años de vida. Independientemente de si la norma se mantuvo o de la antigüedad de la misma, la diferencia en la duración del luto normativo que se realiza establece una jerarquización clara en el estatus del niño y

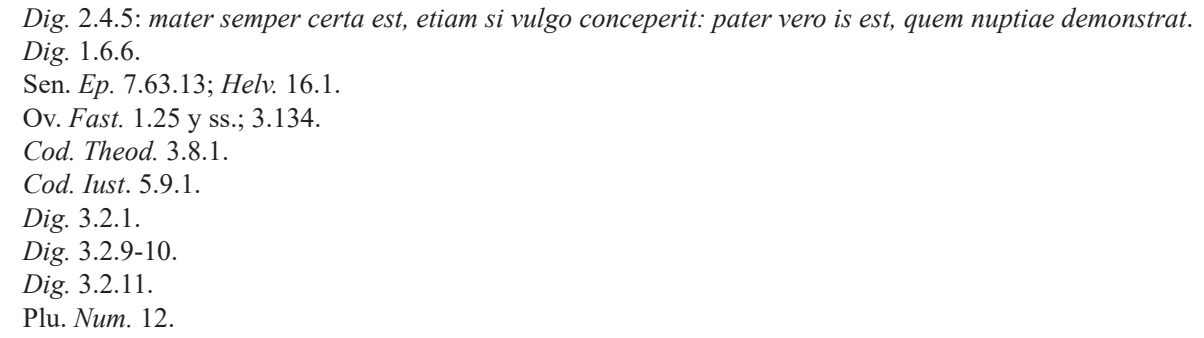


su humanidad. ${ }^{72}$ El neonato, como el nonato, no era considerado como una persona automáticamente por el hecho de su existencia, sino que tenía que pasar por una serie de rituales sociales que lo humanizaran ante los ojos de la comunidad.

Esta diferencia se marcaba también en la variabilidad en el ritual de enterramiento. Los neonatos podían ser enterrados en los aleros de las casas o bajo el suelo de las mismas. ${ }^{73}$ Aún teniendo en cuenta que la presencia infantil en las necrópolis es algo habitual, mientras que es extraño no encontrarla en absoluto, suele asociarse a un rito diferenciado de enterramiento y estar subrepresentada. Los autores romanos refieren una tendencia marcada a inhumar a los niños más pequeños e incinerar a los niños mayores y los adultos, aunque dista de ser algo obligatorio. ${ }^{74}$

\section{Liberi y monstra}

En todo caso, sea cual sea la concepción legal o estatal sobre el feto, todos los derechos del nasciturus se condicionaban necesariamente al nacimiento con vida y aceptación del recién nacido, lo que se especifica en la legislación. Además, se afirma que cualquier derecho del que pueda ser sujeto el feto no afecta a terceras personas, no pudiendo ser la normativa usada en este sentido. El embrión, pues, solo es considerado como nacido o como humano para lo que le interese a sí mismo en cuanto a futuro portador de derechos. ${ }^{75}$ Así mismo, en caso nacimiento de un neonato muerto, no contaba como hijo (ni nacido ni procreado) para ninguna de las ventajas legales y económicas que proporcionaba tener uno o más hijos, ${ }^{76}$ ni tampoco afectaba al testamento ni a la herencia. ${ }^{77}$ Tampoco se consideraba como parto un aborto, provocado o no, e independientemente de lo tardío del mismo (cui mortuae filius exsectus est $){ }^{78}$

Aunque las disposiciones anteriores puedan parecer obvias, hay que tener en cuenta la necesidad de legislar qué se consideraba un hijo, ya que de ello dependían varios privilegios legales. No solo el ius trium liberorum dependía del número de hijos, sino también otros privilegios como la prioridad en la elección de fasces consulares o la elección de magistrados en caso de empate en número de votos. ${ }^{79}$ Todo ello llevó a que se intentaran ficciones como la adopción de hijos, emancipándolos después de obtener el beneficio, contar a los hijos muertos o emancipados y, probablemente, intentar contar los partos de neonatos muertos. ${ }^{80}$

\footnotetext{
Cic. Tusc. 1.39 .93 .

73 Plin. HN 7.16; Fulg. Expos. serm. ant. 7. En ciertas localidades navarras y vascas existió durante mucho tiempo una costumbre similar para los neonatos no bautizados (cf. FERnÁNDEZ CrESPO 2008); pero probablemente sea una pervivencia directa de la costumbre medieval de intentar proporcionar un bautismo simbólico (al caer sobre la tumba el agua del alero) y un enterramiento digno al neonato no bautizado más que una pervivencia directa de una costumbre romana.

74 CAROLL 2012, 41-63. La presencia de enterramientos infantiles ronda el 10\% en necrópolis como la encontrada en la antigua Via Collatina (Roma, Italia), Vía Serenísima (Roma, Italia), Isola Sacra (Ostia, Italia), Sainte-Barbe (Marsella, Francia)... aunque los porcentajes pueden ser mucho más reducidos, como el 3\% de la necrópolis hallada en Saint-Paul-Trois-Châteaux (Francia), o mucho más elevados, como el 39\% de Sétif (Argelia).

5 Dig. 1.5 .7

$76 \quad$ Dig. 1.5.7; 50.16.129.

Dig. 34.5.7.

Dig. 50.16.132.1.

Lex Malacitana 56.

80 GARDNer 1998, 47 y ss.
} 
Un caso diferente sería el de un hijo considerado monstruoso o sin forma humana, ya que, pese a haber llegado a nacer, planteaba un conflicto en cuanto a considerar que ese feto hubiera sido objeto de derecho al no ser considerado completamente humano. Así, el Digesto ${ }^{81}$ recoge la negativa del jurista Paulo a que fueran tenidos entre los hijos legítimos (liberi), salvo que la deformidad se redujese a tener más miembros de lo normal, como por ejemplo, en el caso de polidactilia. Esta disposición tuvo una amplia repercusión en épocas posteriores y, de hecho, en el derecho español sobrevivió hasta 2011, año en el que se reformó el artículo 30 del Código Civil que exigía, para el reconocimiento del hijo, que hubiera sobrevivido más de veinticuatro horas fuera del seno materno y tener forma humana. A partir de ese año, el único requerimiento es haber nacido con vida, sea cual sea la forma del neonato o su supervivencia tras el parto.

Hay que tener en cuenta que los niños nacidos con malformaciones no solo eran descartados por motivos eugenésicos, siendo la excepción permitida a la prohibición de matar a los niños varones en las leyes más primitivas, ${ }^{82}$ sino que tenía unas fuertes connotaciones religiosas. Los niños o los animales nacidos con algún tipo de problema físico muy evidente eran considerados monstra y, por tanto, prodigia. Es decir, que suponían un aviso divino de que algo iba mal y de una ruptura de la pax deorum.

Por todo ello, la eliminación de estos niños y su consideración como algo fuera de las relaciones normales de la familia se debía también a una necesidad de una expiación religiosa, que podía llegar a requerir de la intervención de un sacerdote. Aún así, parece que no todas las deformidades serían consideradas como un prodigio o un miraculum, sino, tal vez, las más espectaculares, como los siameses, la existencia de más miembros de lo normal o la intersexualidad. ${ }^{83}$ Estos portentos parecen haber sido relativamente frecuentes en Roma, aunque siempre por debajo de otros fenómenos como la caída extraordinaria de rayos o los relacionados con plagas y catástrofes. ${ }^{84}$

La figura de los hermafroditas sería un caso especial, que entraría dentro de la categoría de monstra o prodigia, pero cuya figura parece ir normalizándose. Aunque la Ley de las XII Tablas, en teoría, legisla que todo neonato con alguna deformidad o que sea monstruoso debía ser muerto, ${ }^{85}$ y otros autores nos confirman la sentencia a muerte de estos niños, ${ }^{86}$ que eran arrojados al agua. Sin embargo, Tito Livio ya nos habla de la expiación mediante rituales o sacrificio de víctimas mayores ${ }^{87} \mathrm{y}$, aunque en algunas ocasiones recoge el sacrificio ritual del andrógino, parece ligado a épocas de crisis, y en el caso concreto el niño tenía ya nueve años. ${ }^{88}$ Además, hay otros autores, como Plinio, que mencionan también la posibilidad del destierro para alguno de ellos. ${ }^{89}$

\footnotetext{
Dig. 1.5.14.

D.H. 2.15.

ALLÉLY 2003, 127-156.

Para la cuantificación de prodigios y su clasificación en la Roma republicana cf. ALDEA 2010.

Ley de las XII Tablas, tabla IV.

86 Obseq. 22, 27, 32, 34, 36, 47, 48, 50, 53. Sobre los monstra y los andróginos, se habla en detalle en MONTERo 1993.

87 Liv. $22.11 ; 24.10$.

88 Liv. 39.22 .

89 Plin. $H N$ 7.4.36.
} 
Por otra parte, también se recogió en el Digesto la opinión de Ulpiano de que el nacimiento de un hijo demasiado débil o de figura no humana (portentosum, monstrosum, debilem, non humanae figurae, vagitu novum) no debía perjudicar los derechos de la madre a las ventajas de un nacimiento. En este caso, sí que se hace una diferencia entre una pérdida debida a la fatalidad y una provocada por la familia. ${ }^{90} \mathrm{La}$ legislación parece ser contradictoria en este punto, cosa que no resulta sorprendente si se tiene en cuenta la tendencia a la superposición de normas, casos concretos y opiniones de juristas que acaban recogiéndose en los códigos tardíos. El derecho de la madre, en cualquier caso, no se corresponde aquí con un derecho del feto en sí mismo, sino con unas ventajas socioeconómicas (como el ius trium liberorum) que habían ido perdiendo mucho de su significado pronatalista real que habían tenido en un principio y que, en ocasiones, se llegaban a conceder honoríficamente.

Aun así, en algunos casos, la legislación romana especificó la necesidad de que los hijos necesarios para una exención, por ejemplo, de cargos personales o legaciones, fueran supervivientes. No podía contarse el número, pues, de hijos muertos poco después del parto, en la infancia o los que aceptaba Ulpiano para otros casos. ${ }^{91}$

Aun habiendo nacido el hijo, podía llegar a no contarse como tal en caso de no ser reconocido por el padre. Este reconocimiento, cuyos términos latinos tienen un oscuro origen sacral (adgnoscere partum/filium, tollere liberum, suscipere liberum) era potestad del pater familias. ${ }^{92}$ Pese a la idea de libertad total del padre en este caso, en realidad la legislación se encargó de ir limitando este poder con una serie de leyes pro-natalistas, encaminadas a asegurar tanto el mantenimiento de las líneas familiares como un adecuado aporte de soldados al ejército romano. Ya Dionisio de Halicarnaso menciona que resultaba necesario un consejo de cinco personas para poder abandonar a un hijo, ${ }^{93}$ y el Digesto reconoce la capacidad de la madre de obligar al padre al reconocimiento de un hijo mediante una sentencia. ${ }^{94}$ Valerio Máximo recoge también una sentencia de Augusto en la que se permite acceder a la herencia a un hijo, Gayo Tetio, que había sido desheredado por su padre al nacer. ${ }^{95}$ Las causas de dicha decisión no se recogen en el texto, limitándose el autor a atribuirlo a la maldad del padre, además de destacar que no se habría divorciado de la madre, cosa que debería haber hecho si el hijo fuera fruto de un adulterio. Pese a no haber recibido el nombre familiar, ni haber sido aceptado en la familia por el padre, el hijo fue criado y llegó a la edad adulta, aunque no se especifica si en la casa paterna, en la de algún familiar o por una persona ajena.

Del mismo modo, la lex Cornelia de sicariis et veneficis incluye en algún momento la restricción de la capacidad del padre de ejecutar al hijo, estableciendo el derecho del mismo a ser oído y solo ser ejecutado tras haberse presentado una acusación formal ante el prefecto o el gobernador provincial. ${ }^{96}$

También, por sentencia, se podía obligar a los padres a alimentar a los hijos (y a mantenerles en general). Esta obligación recaería en el padre en caso de demostrarse la legitimidad de los hijos, o en la madre en caso de que no hubiera un padre

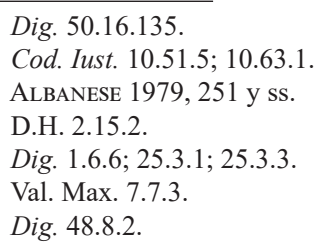


conocido o unido legalmente a esos hijos por ausencia de nupcias legales o cualquier otro motivo. El abuelo paterno también se vería obligado en caso de que los nietos estuvieran bajo su potestad o faltaran los padres. De todos modos, la obligación era recíproca y los hijos se verían obligados a mantener a sus padres en caso de necesidad. ${ }^{97}$

En el derecho tardío también se limita la capacidad de los padres de vender a los hijos, hasta acabar prohibiendo la práctica, prohibiéndose también el comprar personas libres. ${ }^{98}$ No parece que fuera fácil la erradicación de la práctica, y en época del gobierno de Valentiniano, Teodosio y Arcadio se legisla que los que hubieran sido vendidos por sus padres deberían ser puestos en libertad, recuperando su condición de ingenuos en vez de pasar a ser libertos. ${ }^{99}$

Igualmente, se restringiría la capacidad de abandonar al recién nacido, comparándolo con el infanticidio directo. El legislador Paulo afirma que, legalmente, se puede considerar igual a matar al hijo, no solo a quien lo mata tras el parto (necare videtur non tantum is, qui partum perfocat), sino también a quien lo expone (qui abiicit) o a quien le niega los alimentos (qui alimonia denegat). Aun así, se considera que el que expone al hijo lo hace buscando la misericordia ajena (qui publicis locis misericordiae causa exponit), y probablemente se esperara que el hijo sobreviviera. ${ }^{100}$

Cabe la posibilidad de que en la legislación más tardía o en algunos autores las restricciones al derecho de vida y muerte que implicaba la patria potestas se vieran influidas por la piedad o por elementos filosóficos, por extenso estoicismo o cristianismo. Pero, pese a estas consideraciones, tampoco puede asociarse automáticamente la protección legal romana del neonato a un reconocimiento implícito de su humanidad.

Puede encontrarse otra razón fundamental en la legislación romana contraria al aborto, como es la asociación de los remedios abortivos con venenos y pociones mágicas, además de con la violencia autoinfligida o infligida a terceros. Por ello, se añade en algún momento una norma dentro de la lex Cornelia de sicariis et veneficis castigando con el destierro a la mujer que abortase. ${ }^{101}$ La adición parece tardía, como afirman Enzo Nardi o Bernardo Santalucía. Mientras el primero considera sugerentes las teorías sobre una posible influencia cristiana, fuera esta directa o indirecta, ${ }^{102} \mathrm{el}$ segundo cree que las modificaciones de la ley silana datarían de época más temprana, a principios de la época imperial. ${ }^{103}$ Aún con el añadido del aborto como elemento punible en la ley, queda claro que no se estima como homicidio y, por tanto, no se castiga con la pena capital.

En la misma ley se castiga también a quien pudiera vender mala medicamenta, aunque se especifica que no todos los medicamentos se incluyen en esta categoría, aunque pudiesen resultar peligrosos. ${ }^{104}$ En todo caso, el castigo, en esta situación, va más unido al peligro que suponen las sustancias y a la posibilidad de muerte de la madre, que a la misma práctica del aborto. De hecho, también se castiga la venta de

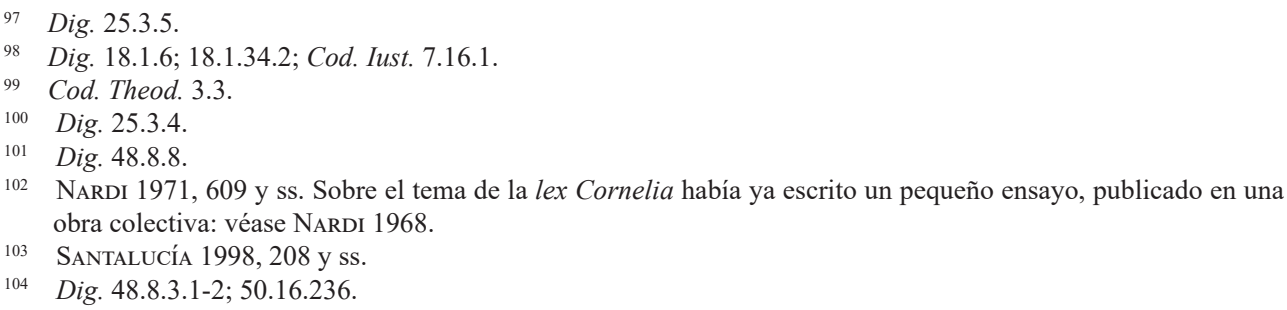


sustancias peligrosas, como las cantáridas, el buprestis o la mandrágora, ${ }^{105}$ usadas como afrodisíacos (uso que se explicita en la norma), anticonceptivos y abortivos. ${ }^{106}$

Aun así, se puede percibir cierto grado de moral sexual en la ley, unido a cierta protección personal o de los derechos de algunos individuos. Un buen ejemplo es la prohibición adrianea de la castración, sea sobre libres o esclavos, voluntaria o forzada, llegando a castigarse con la muerte, aunque haya también penas de confiscación de bienes. ${ }^{107}$

En el Digesto se condena la venta de pócimas amatorias o abortivas, específicamente, por el mal ejemplo que supone el comercio con este tipo de sustancias, asociadas a la magia o el adulterio, ${ }^{108}$ esta última vinculación es prácticamente explícita por incluirse en la misma normativa la condena a quien desflorara a una doncella no casadera. ${ }^{109}$

La venta y fabricación de venenos también se pena con la muerte o el destierro, dependiendo de la categoría social del condenado. ${ }^{110}$ La pena se agrava si el veneno es usado para matar a alguien, siendo especialmente grave el caso de un médico que colabore en un parricidio. ${ }^{111}$ Así pues, el control de las sustancias abortivas, anticonceptivas, peligrosas o las recetas afrodisíacas suponía para el médico una cuestión vital para el desarrollo de su carrera, ya que hay que tener en cuenta que los médicos tenían que ser moralmente intachables para ser contratados por los municipios, ${ }^{112}$ o para la conservación de la propia vida y libertad.

\section{Conclusiones}

En conclusión, a la hora de valorar la figura del feto en la legislación romana se aprecian varios factores en conflicto, que cristalizan en una normativa compleja y no siempre coherente. Hay que tener en cuenta que, como decía Angus McLaren, aunque la mujer haya ganado, tradicionalmente, estatus a través de la maternidad, también era importante el modo y el tiempo en que se lleva a término dicha maternidad. ${ }^{113}$ Así pues, la valoración social que obtiene la mujer a través de sus hijos no obsta para que la legislación tenga en cuenta otro tipo de factores o el feto tenga un valor relativo y condicionado, en cualquier caso, al nacimiento.

Por un lado, la legislación tiende a ser garantista con los derechos de un futuro ciudadano, aplazando condenas a muerte o garantizando su libertad en caso de haber sido la madre libre en algún momento del embarazo, así como con su patrimonio y vinculación familiar, legislando sobre su inclusión en testamentos y legados.

Por otro lado, la asociación de prácticas como el aborto y la anticoncepción con la magia y el adulterio las convierten en prácticas socialmente peligrosas, más allá de su relación con la fertilidad, la familia o el propio embrión. No hay que olvidar, por ejemplo, que en las amnistías decretadas por emperadores como Constantino,

\footnotetext{
105 Dig. 48.8.3.2.

106 Para el uso como anticonceptivo de estos elementos véase: Hp. Mul. 1.74, 78, 84, 91; Mul. 2.135, 206; Superf. 33; Nat. Mul. 18.32.109; Dsc. 2.61.1; 4.75.

107 Dig. 48.8.4-6.

108 Dig. 48.19.38.5.

109 Dig. 48.19.38.3.

110 Dig. 48.19.28.9.

111 Dig. 48.9.2.

112 Dig. 50.9.1; Cod. Theod. 13.3.1-5.

113 MCLAREN 1990, 5 y ss.
} 
se excluyen los convictos por homicidio, magia o adulterio, quedando, en algunos casos, por encima de los delitos de alta traición. ${ }^{114}$

Así pues, el tratamiento legal del embarazo, el parto o el control de natalidad no se centran tanto en la existencia de un nuevo ser humano o en su esperanza, sino en toda una serie de condiciones y condicionantes legales y sociales que afectan al propio concepto de familia y comunidad. Se hace necesario, pues, estudiar este tipo de interacciones entre sociedad, moral y legislación para llegar a comprender mejor los discursos y visiones romanas sobre la reproducción, la familia y el Estado.

\section{Referencias bibliográficas}

Adams, J. N. (1982): The Latin sexual vocabulary, London.

Albanese, B. (1979): Le persone nel diritto privato romano, Palermo.

AldeA, J. M. (2010): "Religión, política y sociedad: los prodigia en la Roma republicana", El Futuro del Pasado 1, 279-293.

AlléLY, A. (2003): “Les enfants malformés et considérés comme prodigia à Rome et en Italie sous la République”, Revue des études anciennes, 105/1, 127-156.

ArÉvalo, W. (2011): “Adoptio a muliere facta en derecho romano y en la tradición jurídica española”, RIDROM: Revista Internacional de Derecho Romano 7, 156-198.

Brockliss, L. - Montgomery, H. (2010): "Introduction”, [en] L. Brockliss - H. Montgomery (eds.), Childhood and violence in the Western Tradition (=Childhood in the Past Monograph Series 1), Exeter.

Brown, P. (1993): El cuerpo y la sociedad. Los cristianos y la renuncia sexual, Barcelona.

CARoll, M. (2012): “No part in earthly things'. The Death, Burial and Commemoration of Newborn Children and Infants in Roman Italy", [en] M. Harlow - L. Larsson Lovén (eds.), Families in the Roman and Late Antique World (=The Family in Antiquity 2), London-New York, 41-63.

CAstillo, A. (1988-89): "Legislación romana y liberación femenina: Una relación inconsciente", Lvcentvm 7-8, 161-169.

Cid LóPEz, R. M (2007): “Imágenes y prácticas religiosas de la sumisión femenina en la Antigua Roma. El culto de 'Juno Lucina' y la fiesta de 'Matronalia', Studia historica. Historia antigua 25, 357-372.

CID López, R. Ma (ED.), (2009): Madres y maternidades. Construcciones culturales en la civilización clásica, Oviedo.

Congourdeau, M. H. (2004): “Genèse d'un regard chrétien sur l'embryon”, [en] V. Dasen (ed.), Naissance et petite enfance dans l'Antiquité. Actes du colloque de Fribourg, 28 novembre-1er décembre 2001 (=Orbis Biblicus et Orientalis 203), Fribourg, 349-362.

Corbett, P. E. (1930): The Roman Law of Marriage, Oxford.

Crawford, S. - ShePerd, G. (EDS.), (2007): Children, Childhood and Society, Oxford.

DASEN, V. - SPÄTH, T. (EDS.), (2010): Children, memory, and family identity in Roman culture. Roman Family Conference (5 ${ }^{\text {th }}:$ 2007: Fribourg, Switzerland), Oxford.

\footnotetext{
114 Cod. Theod. 9.38.1.
} 
Domínguez Arranz, A. (2010): "La maternidad como base del discurso político en el Imperio Romano", [en] R. M $\mathrm{M}^{\mathrm{a}}$ Cid López (ed.), Maternidad/es: Representaciones y realidad social. Edades Antigua y Media, Madrid, 167-185.

EsCOBAR, A. (2012): "Oppressed voice and oppressing silence: some ancient attitudes towards abortion and infanticide", Euphrosyne, Revista de filología clássica 40, 109-122.

FERnÁNDEZ CReSPO, T. (2008): “Los enterramientos infantiles en contextos domésticos en la Cuenca Alta/Media del Ebro: a propósito de la inhumación del despoblado altomedieval de Aistra (Álava)", Munibe (Antropologia-Arkeologia) 59, 199-217.

Flemming, R. (2000): Medicine and the making of Roman women. Gender, nature, and authority from Celsus to Galen, Oxford-New York.

Franciosi, G. (1989): Famiglia e persone in Roma antica. Dall'età arcaica al principato, Torino.

GARDner, J. F. (1998): Family and Familia in Roman Law and Life, Oxford.

George, M. (ED.), (2005): The Roman Family in the Empire. Rome, Italy, and Beyond, Oxford.

GonzÁLEZ, P. (2015): "Prostitutas y control de natalidad en el mundo grecorromano/ Prostitutes and Birth Control in the Greco-Roman World”, [en] P. Hernández et alii (eds.), Amor y sexualidad en la Historia, Salamanca, 137-156.

KAPPARIS, K. (2002): Abortion in Ancient World, London.

Knibiehler, Y. - Fouquet, C. (1983): La femme et les medecins, Paris.

LAJeunesse, M. (2015): "La mère dans le Code de Gortyne : reconnue juridiquement, mais pas autonome pour autant", Cahiers "Mondes anciens" 6 [on line: http://mondesanciens. revues.org/136], consultado el 29 de enero de 2015 (http://dx.doi.org/10.4000/ mondesanciens.1367).

Loraux, N. (2007): Nacido de la tierra: Mito y politica en Atenas, Buenos Aires.

McLaren, A. (1990): A History of Contraception. From Antiquity to the Present Day, Oxford.

Montero, S. (1993): "Los haruspices y la moralidad de la mujer romana", Athenaeum. Studi Periodici di Letteratura e Storia dell'Antichità 81, 647-658.

Mustakallio, K. (ED.), (2005): Hoping for continuity. Childhood, Education and Death in Antiquity and Middle Ages (=Acta Instituti Romani Finlandiae 33), Roma.

NARDI, E.

(1968): “Credo stoico e portata delle leggi Cornelia e Pompeia sull'omicidio", [en] Studi in onore di Giuseppe Grosso, Torino, vol. I, 313-319.

(1971): Procurato aborto nel mondo greco romano, Milano.

Needham, J. (1959): A History of Embryology, Cambridge.

Noonan, J. T. (1969): Contraception et mariage. Évolution ou contradiction dans la pensée chretienne?, Paris.

NúÑEZ, I. (2009): "Progresivo y limitado reconocimiento de la figura materna en el derecho romano. De la cesión del vientre al ejercicio de la tutela", [en] Cid López (ed.), 2009, 255-291.

Pedregal, A. (2010): "Maternidad y madres en la tradición cristiana (siglos II-IV D.E.): Discursos sin memoria”, [en] Cid López (ed.), 2010, 111-131.

Rubiera Cancelas, C.

(2011): "Las esclavas en la regulación jurídica. Algunas notas desde el Digesto", El Futuro del Pasado: revista electrónica de historia 2, 439-451.

(2014): La esclavitud femenina en la Roma antigua: famvlae, ancillae et servae (=Colección Démeter 5), Oviedo. 
Saller, R. P. (1994): Patriarchy, property and death in the Roman family (=Cambridge Studies in Population, Economy and Society in Past Time 25), Cambridge.

Santalucía, B. (1998): Diritto e processo penale nell'antica Roma, Milano.

Sciortino, S. (2006): "Sull'adozione da parte delle donne", Annali del Seminario Giuridico dell'universitá di Palermo 51, 309-349.

SuÁrez, C. (ED.), (2009): Maternidades: (de)construcciones feministas, Oviedo.

Tetlow, E. M. (2005): Women, Crime and Punishment in Ancient Law in Society, Volume 2: Ancient Greece, New York-London.

TuBERT, S. (ED.), (1996): Figuras de la madre, Madrid.

ZANKeR, P. (1992): Augusto y el poder de las imágenes, Madrid. 